\title{
Valuing Road User's Willingness to Pay to Reduce Traffic Congestion in Klang Valley, Malaysia
}

\author{
K. Mahirah ${ }^{1}$, A. A. Azlina ${ }^{1}$, Izyan Nazirah ${ }^{1} \&$ Ridzuan Yacob $^{2}$ \\ ${ }^{1}$ School of Social and Economic Development, Universiti Malaysia Terengganu (UMT), Kuala Terengganu, \\ Terengganu, Malaysia \\ ${ }^{2}$ Centre for Fundamental and Liberal Education, Universiti Malaysia Terengganu (UMT), Kuala Terengganu, \\ Terengganu, Malaysia \\ Correspondence: K. Mahirah, School of Social and Economic Development, Universiti Malaysia Terengganu \\ (UMT), 21030 Kuala Terengganu, Terengganu, Malaysia. E-mail: mahirah.k@umt.edu.my
}

Received: June 23, 2015 Accepted: October 16, 2015 Online Published: October 26, 2015

doi:10.5539/ass.v11n25p48 URL: http://dx.doi.org/10.5539/ass.v11n25p48

\begin{abstract}
Traffic congestion has become one of the issues in big city that can be denied. Time spent in traffic is miserably wasted and it creates negative externalities to the road users. The main objective of this study is to examine the road users' willingness to pay for reducing traffic congestion in Klang Valley, Malaysia. A primary survey data with a total of 366 respondents is used for the analysis. Different price bids with 3 groups of toll payments were offered to the road users in order to avoid bias in analyzing their willingness to pay. The results demonstrate that the mean willingness to pay is about RM1.95 for toll payment in Klang Valley highways. The results also showed that household income, respondents' occupation and price bid toll payment have significant effects on the willingness-to-pay to reduce traffic congestion. Based on these findings, several policies have been recommended.
\end{abstract}

Keywords: contingent valuation method, traffic congestion, transportation, willingness to pay

\section{Introduction}

Poor planning, lack of buses and a surge in car ownership have contributed to the already maddening congestion in Klang Valley, the conurbation where Kuala Lumpur, the capital city of Malaysia is situated. Many parts of the Klang Valley, like the rest of the country, still do not have proper access to public transport. Providing better quality public transport service is a challenge in the Klang Valley, as the country struggles to meet the transport requirements fundamental to the sustaining of the investment and thus the economic development. Adding to the problem is the increasing urban population growth over the last few years. The government has implemented various strategies which are aimed at simultaneously increasing usage of public transportation and decreasing private vehicles through the availability of a better public transport system in the city. Worsening traffic congestion has negative effects on the community as well. Traffic congestion generates external costs such as increasing air and noise pollution, higher of probability of accidents, and extra travelling time. Emergency services such as ambulances, police cars and fire trucks would be hampered from functioning effectively as they struggle to reach their destinations and it creates more stress for drivers, cyclists and pedestrians.

Increased highway construction is necessary and certainly a practical way to reduce traffic congestion despite its huge outlay and maintenance cost. As it takes a substantial period of time for the highway construction to be completed, the poor forecast of usage capacity means that by the time they are ready, most were found to be insufficient to cater for the rapid growth of vehicles commuting on the road, therefore leading to the worsening of traffic congestion. The intensity of traffic problem differs between cities and it is obviously more congested in cities and states with a bigger population. Roads are a common property resource, by virtue of the fact that the public are free to use them, with very few restrictions. The presence of a driver on the road reduces the speed of the other vehicles and executes a cost on traffic that a driver does not have to pay when road use is free of charge.

Klang Valley demonstrates a feature of developing market economies. The Klang Valley consists of cities and suburbs; integration between these cities is very high, with a highly developed road network and an expanding 
rapid transit system. Many expressways crisscross the metropolis which means the use of cars is the most convenient way to get around. Conversely, it has made the Klang Valley's notorious traffic jams to span for whole kilometers of the expressways and making driving during peak hours become quite exhausting to the people. The traffic congestion has reached a very serious level in the entire area. Though many investments have been made by the government such as construction of new highways and the expansion of the rapid transit system, traffic congestion is still worsening and is hurtling towards a critical level. As in the other developing countries, pollution, road traffic accidents and other road transport externalities are very common. From an economic point of view, the presence of negative externalities in the market makes it impossible to achieve an efficient equilibrium as the total benefit of road transport to maximize.This is because that increasing any road user's benefit will reduce another road user's benefits (Santos, Behrendt, Maconi, Shirvani, \& Teytelboym, 2010). In 2010, the total numbers of all types of motor vehicles on the Malaysian roads were 21.25 million units, an increase of $11.74 \%$ from year 2009. The highest number of registered vehicles in 2010 is in the Kuala Lumpur Federal Territory with 4,914,992 of vehicles, followed by Johor with 2,900,984 of vehicles and Selangor with 2,209,770 of vehicles (Road Transport Department, 2010).

This study aims to determine road user's willingness to pay (WTP) to reduce traffic congestion in Klang Valley highways. An application of Contingent Valuation Method (CVM) will be used to estimate road user's WTP for congestion reduction so that in future they will enjoy traffic improvements by reducing road transport externalities. Hence, in valuing improvements to current exposure that would lessen future risks, it is significant to know how much people would be willing to pay for policies which give benefits of such improvements in the future. Though application of valuation techniques are increasingly widespread in its usage for environmental goods and services in developed countries, the valuation of transport externalities in less developed countries is still at an early stage (Ortuzar, Cifuentes, \& Williams, 2000). Figure 1 presents a map of Klang Valley city roads and highways.

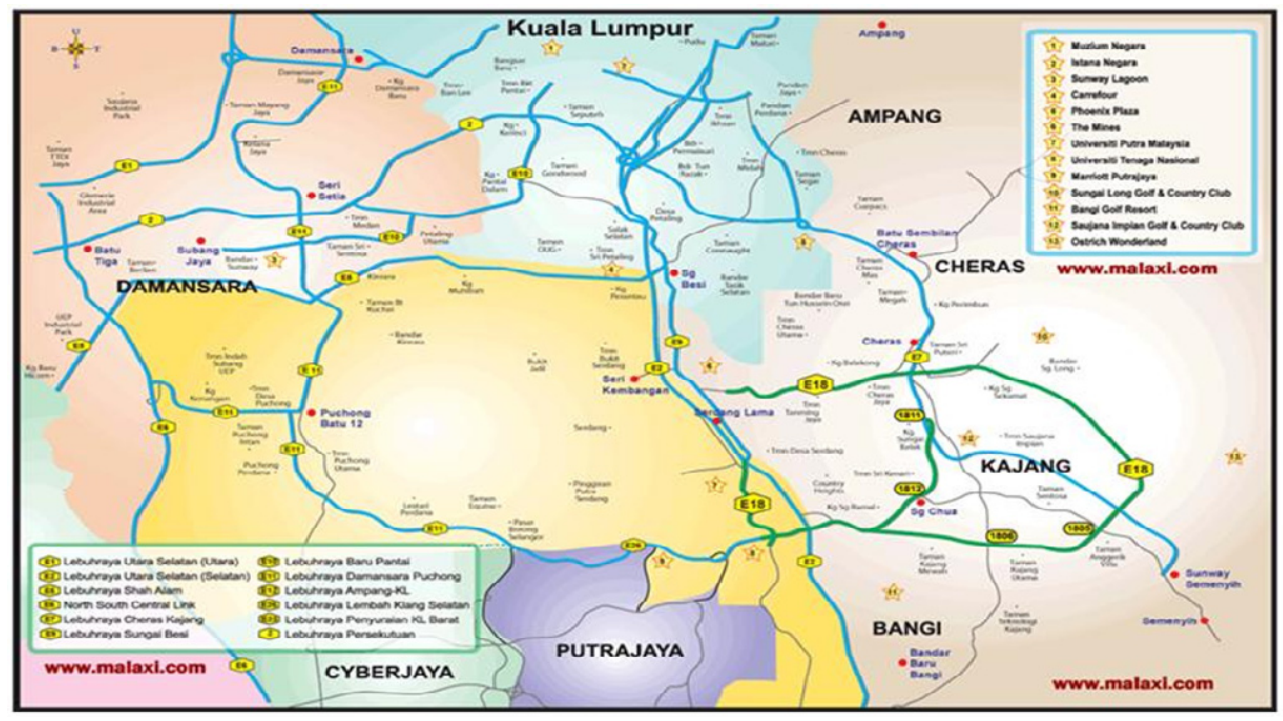

Figure 1. Map of Klang Valley city roads and highways

The rest of the paper is structured as follows. Section 2 reviews the relevant literature. Section 3 explains the methodology and Section 4 reports the empirical results. Section 5 discusses the policy implications of the findings and concludes the paper.

\subsection{Literature Review}

There is a large volume of published studies analyzing the willingness to pay (WTP) in a variety of areas. In the early development of literatures, WTP has been used as a basic approach to quantify the values and the benefits of non-market goods and services given that it can precisely reflect the consumer's preferences. According to Tietenberg and Lewis (2008), WTP is used by the environmental economist to value the goods that are non-traded and without property rights such as air, water, forests and wildlife populations. To date, researchers from numerous disciplines have used it for policy planning purposes. For instance, Gerking et al. (2014) used it to determine the value improvements in human health, while Sexton and Sexton (2014), used it to evaluate the 
willingness to pay for hybrid vehicle. Kaliba et al. (2011) applied it as a tool to value education system and Surendran and Sekar (2010) used it to study the forest eco-system.

Likewise, WTP has been used to value transportation related goods such as emissions of pollutions to the air, the emission of noise, improvement in transportation and improvement in road surface. A wide range of applications has been reported by, among others, Bjoner (2004), Fosgerau and Bjorner, 2006, Eboli and Mazzulla, (2008), Asensio and Matas (2008) and Takada and Fujiu (2010). In the context of traffic congestion, it creates a negative externality since it entails a loss of travel time for the commuters due to slower speeds, longer trip times and increased queuing, thus imposing delays on others. In addition, congestion externalities also include cost in the form of fuel cost, air pollution, noise, global warming and safety risks.

Brownstone et al. (2003) based on their study on San Diego highway congesting pricing revealed that the preference for fast track lanes was normally distributed which peaks at the highest toll charges. They estimated that the median willingness to pay to avoid travel time averaged US\$30 per hour, a figure higher than those determined through studies using revealed preference techniques. With respect to the determinants of WTP for a reduction in travel time in San Diego, they found that women, middle age cohorts and those with higher income and higher education level are willing to pay for faster transportation. Glazer and Niskanen (2000) in their transport study consider reassignment on highway users, that is, shifting use of highways from one to another to avoid traffic congestion versus payment of toll charges. Their novel considerations are a toll on a slow mode, rather than inducing some commuters to stop traveling, may shift to fast mode; and a toll on a fast mode because of high toll charge may cause commuters to switch to slow mode causing former users to travel less. Their findings seemed to favor the use of fast mode in the light of traffic congestion.

Calfee and Winston (1998) attempted to estimate willingness to pay to reduce travel time in the U.S. Based on the stated preference data and using toll fees as a proxy to measure individuals' WTP to avoid traffic congestion, they observed that income is not significantly correlated with the value of travel time.Dodgson and Lane (1997) provide procedural estimates of costs on road congestion to road users in Great Britain in 1996. Their study was based on road network of 26 different types of road with nine different time periods in the week. They used the functional relationship between the speed-flow and traffic congestion. The important part of this study is the detailed description about different congestion cost. The estimates are based on traffic flow data for different road network at different times of the day; information on traffic flows and speeds on the road network; estimates of the values of travel time for businesses, non-businesses and nonworking time; fuel consumption and other vehicle operating costs-traffic speeds, costs of petrol and diesel fuel were used in their analysis.

\section{Methodology}

\subsection{Contingent Valuation Method}

This study comprises a determination of the willingness to pay to reduce traffic congestion and transport externalities. Congestion can be regarded as an external effect that road users effect on each other. Contingent Valuation Method (CVM) is a method in estimating the value that people placed on goods and services which do not have an existing market. The application involves asking people directly about their willingness to pay (WTP) in order to attain the goods and services rather than interfering them from observed behaviors in a regulated market place. The CVM is very commonly used in valuing environmental good and service problems, which are very difficult to observe market transactions under the desired conditions.

The CVM is a widely used non-market valuation technique and has many advantages in its application. For instance, the method can elicit respondents' maximum willingness to pay for different levels of service that are 'not currently available' yet (Wedgwood \& Sansom, 2003). Hence, it can estimate WTP for hypothetical improvements in the quality of service. Second, the method involves asking respondents directly about their maximum or minimum willingness to pay for goods or services (Pearce et al., 2002). The situation is hypothetical and reasonable as it also consists of an explanation of these goods and services. Third, the method focuses on the non-market goods or services which require a clear analysis as a whole.

However, this method also leads to some biases in the study. There are some problems in its application such as strategic bias when the respondents have not answered truthfully or accurately and they do not reveal real preferences when asked about their WTP (Tietenberg, 2000). Nature of bias occurs when the respondents give an answer which is not their actual valuation in order to influence the final outcome. Starting point bias arises in the iterative bidding framework when the initial bid influences respondents on final bids (Boyle, Bishop and Welsh, 1985). This bias may manipulate the respondent's answer regarding their WTP. Yea saying bias occurs when the respondent tries to please the interviewer by giving a false response, rather than expose their true views. The difficulty in conducting the CVM is the difficulties for researchers to translate the concepts behind the method 
such as an economic value and "maximum willingness to pay" or "minimum compensation that respondents are willing to accept" (Whittington, 1998).

The method involves a survey based technique of monetary valuation used to determine people's preferences expressed in terms of WTP. In this study, the method applies a proper design questionnaire in order to determine the valuations or bids of road users about an increase or decrease in the amount of toll payment at Klang Valley highways so that they can enjoy road network improvements and reduce transport externalities. This study provides a theoretical utility framework by following Hanemann (1984) on road user's response for improvements in traffic congestion in Klang Valley highways. They have the indirect utility functions since they consider their preferences in terms of what they consume rather than the prices. Since improvements in traffic congestion is considered as an economic good, WTP is expected to be nonnegative random variable (Hanemann, 1989). WTP as a dependent variable for road user's willingness to pay for changes in traffic congestion at Klang Valley highways and it can be expressed in a linear regression model as in Equation 1 below;

$$
\mathrm{WTP}=\beta_{0}+\mathrm{INC} \beta_{1}+\mathrm{PBID} \beta_{2}+\mathrm{OCC} \beta_{3}+e
$$

Where:

WTP = Probability of saying "Yes" or "No" to offered prices.

PBID $=$ Price Bid toll payment expressed in Ringgit Malaysia (RM).

HINC $=$ Household's monthly income expressed in Ringgit Malaysia (RM).

OCC $=$ Occupation of the respondents.

In the CVM, only a price is offered to respondents. Bishop and Heberlein (1980) were the pioneers of the method when they first used the single-bounded dichotomous choice CVM or closed ended format in a study. The respondents are asked whether or not they would pay or accept a specific single amount for a program or policy in question. The method involves asking respondents such as "Would you be willing to pay an increase of $5 \%$ from current toll payment in order to have a reduction in traffic congestion and improvements in traffic in the future?" When a hypothetical price is revealed, the respondents decide whether to "take it" or "leave it". The dichotomous choice CVM uses closed-ended format that can be answered using a simple "yes" or "no". As established by Hanemann et al. (1991) "the dollar amount is treated as a threshold", the individual will answer "yes" if the good is valued more highly than the threshold dollar amount which is stated, if not the individual answers "no". When a respondent is asked to pay a specific amount of price bid due to an improvement in traffic in the highways, there will be a probability to attain "yes" or "no" answers. Hence, it can be presented by using model formulation which followed Hanemann et al. (1991) as below;

$$
\begin{gathered}
\text { Probability }\{\mathrm{No}\}=\text { Probability }\left\{\mathrm{WTP}_{\max }<P R I C E\right\}=G(P R I C E ; \theta) \\
\text { Probability }\{\text { Yes }\}=\text { Probability }\left\{\mathrm{WTP}_{\text {max }}>\text { PRICE }\right\}=1-G(\text { PRICE; } \theta)
\end{gathered}
$$

Where, PRICE is the proposed toll payment price bid, $\mathrm{WTP}_{\max }$ is the maximum willingness to pay (WTP) and $G$ $(P R I C E, \theta)$ is the cumulative distribution function (CDF) of WTP. This study uses CDF to model regression since the response variable is dichotomous, by taking 0 - 1 values (Gujarati, 2003). Equation 2 calculates the probability of a respondent not willing to pay an offered amount where the proposed price bid (PRICE) amount is more than road user's willingness to pay. Equation 3 on the other hand, describes the resulting probability of answering "yes" to the offered price amount, if the offered price is lower than their maximum willingness to pay.

\subsection{Logit Model}

This study employs logit model, as $\operatorname{Prob}^{\mathrm{Y}}{ }_{\mathrm{i}}$ (probability of answering "yes") takes the form and the approximate value of $e$ (exponential function) is 2.718 . The probability of the road user is willing to pay RM $X$ and saying "yes" is specified in Equation 4 below;

$$
\operatorname{Prob}_{\mathrm{i}}^{\mathrm{Y}}=\left[1+e^{-k}\right]^{-1}
$$

Where, $k$ is the logit prediction if consumer's respond "yes" or "no" for WTP questions. The $r_{i}=1$ demonstrates the road user $i$ would say "yes" to the proposed price and responses "no" to the question when $\mathrm{r}_{i}=0$. The dichotomous choice logit model is derived from random utility context in consumer decision making. This model uses a choice between two mutually exclusive options.

$$
\begin{aligned}
& r=1 ; \text { if WTP }>n \\
& r=0 ; \text { if WTP }<n
\end{aligned}
$$

Where, ris road users who take part in the survey and $n$ is one of the $x$ 's variables referring to Equation 7. The 
respondents answer "yes" or "no" to a hypothetical price and true WTP is either greater or less than $n$.

$$
\mathrm{WTP}=x \beta+e
$$

The log-likelihood function for single bounded CVM is as in Equation 8 below:

$$
\log \mathrm{L}^{\mathrm{CVM}}=\Sigma-c \log \{1+\exp [(t-x \beta) / k]\}+(1-c) \log \{\exp [(t-x \beta) / k] /(1+\exp [(t-x \beta) / k]\}
$$

It can be shortened to as follows:

$$
\log \mathrm{L}^{\mathrm{CVM}}=\Sigma(1-c)\{(t-x \beta) / k\}-\log \{1+\exp [(t-x \beta) / k]\}
$$

\subsection{Sampling Procedure}

The data for this study were collected from 366 road users of highways inKlang Valley in a survey between January to March 2014. The respondents were told that the study will help to reduce transport externalities and enable the provider and authorities to understand the users' expectations regarding improvements in daily traffic. The study started with pre-test 2 months earlier with 30 road users as respondents. The study offered 3 groups of bidding price which are made up of an increase and a decrease of 5\%,10\% and $15 \%$ from the current toll payments. Diversification of bids is a strategy to evade the possible "starting point bias". Alberini (1995) mentioned that there is no accepted viewpoint in the literature on the number of different bids offered in the CVM. Table 1 presents a distribution of respondents who are Klang Valley highway users that get involved in this study. According to Mitchell and Carson (1989), the appropriate of sample sizes are between 200 and 2500 of respondents. Thus, this study is able to attain the suitable sample size to conduct CVM.

Table 1. Distribution of respondents in Klang Valley highways

\begin{tabular}{cccc}
\hline Highways & Frequency & $\begin{array}{c}\text { Percentage } \\
(\%)\end{array}$ & $\begin{array}{c}\text { Current Toll payment in Ringgit Malaysia (RM) (Before } 15^{\text {th }} \text { October } \\
2015)\end{array}$ \\
\hline AKLEH & 21 & 5.7 & 1.50 \\
DUKE & 42 & 11.5 & 2.00 \\
KESAS & 100 & 27.3 & 2.20 \\
KLP & 21 & 5.7 & 2.50 \\
LDP & 64 & 17.5 & 1.60 \\
LEKAS & 57 & 15.6 & 1.90 \\
LKSA & 12 & 3.3 & 1.20 \\
NPE & 15 & 4.1 & 1.60 \\
SILK & 34 & 9.3 & 1.00 \\
Total & $\mathbf{3 6 6}$ & $\mathbf{1 0 0}$ & \\
\hline
\end{tabular}

Source. Lembaga Lebuhraya Malaysia, 2014

\subsection{Computations of Mean and Total Willingness to Pay}

The estimation of mean WTP can be calculated using the equation derived by Cameron (1988) which is as follows:

$$
\text { Willingness to pay }=\frac{\beta_{0}+\sum_{\mathrm{i}-2}^{\mathrm{n}} \beta_{\mathrm{i}} \mathrm{X}}{-\beta_{1}}
$$

Where $\beta_{0}$ is estimated constant, $\beta_{I}$ is the coefficient for the price bid, and $\beta_{i}$ is the coefficient for socio-economic characteristics of respondents.

\section{Results and Discussion}

This section presents the findings of the contingent valuation survey using a descriptive and econometric analysis.

\subsection{Results of Descriptive Analysis}

\subsubsection{Socioeconomic and Demographic Characteristics}

Table 2 summarizes the general demographic and socioeconomic characteristics of the 366 respondents in our 
sample. The distribution of the respondents according to gender shows most of the respondents $(55.2 \%)$ were females. With respect to the respondent's marital status, more than half of the respondents $(44.3 \%)$ are formally married. The educational attainment level of respondents shows that most of the respondents have a high education level. Almost $52.7 \%$ of the respondents have a degree, while $44.2 \%$ have diploma and $1.9 \%$ have Master/PhD. Respondents with secondary education represent only $0.8 \%$ of the sample. Respondents were asked to state their occupation, as presented in Table 2 indicates that $57.4 \%$ of the respondents are involved in the private sector. The percentage for civil servants and business sector are $28.1 \%$ and $14.5 \%$, respectively.To capture the effect of household income on willingness to pay to reduce traffic congestion, households in the sample are classified into six income groups. In the sample, around $41 \%$ of all respondents have a monthly income from RM1, 001 - RM5, 000. In terms of area distribution, the highest percentage (53.6\%) of respondents was from Shah Alam followed by Bangi and Putrajaya (26.2\% and 20.2\%) respectively. The largest proportion $(62.8 \%)$ of the respondents is in the 21-30 years age group.

Table 2. Characteristics of the respondents $(n=366)$

\begin{tabular}{|c|c|c|}
\hline Characteristics & Frequency & Percentages \\
\hline \multicolumn{3}{|l|}{ Gender } \\
\hline Male & 164 & 44.8 \\
\hline Female & 202 & 55.2 \\
\hline \multicolumn{3}{|l|}{ Marital status } \\
\hline Single & 204 & 55.7 \\
\hline Married & 162 & 44.3 \\
\hline \multicolumn{3}{|l|}{ Education } \\
\hline Secondary & 3 & 0.8 \\
\hline Diploma & 162 & 44.2 \\
\hline Degree & 193 & 52.7 \\
\hline Master/PhD & 7 & 1.9 \\
\hline Others & 1 & 0.4 \\
\hline \multicolumn{3}{|l|}{ Occupation } \\
\hline Civil servants & 103 & 28.1 \\
\hline Private & 210 & 57.4 \\
\hline Business & 53 & 14.5 \\
\hline \multicolumn{3}{|c|}{ Household Income } \\
\hline$\leq 1,000$ & 17 & 4.6 \\
\hline $1,001-5,000$ & 150 & 41.0 \\
\hline $5,001-10,000$ & 98 & 26.8 \\
\hline $10,001-15,000$ & 66 & 18.0 \\
\hline $15,001-20,000$ & 29 & 7.9 \\
\hline $20,001>$ & 2 & 2.0 \\
\hline \multicolumn{3}{|l|}{ Area } \\
\hline Bangi & 96 & 26.2 \\
\hline Putrajaya & 74 & 20.2 \\
\hline Shah Alam & 196 & 53.6 \\
\hline \multicolumn{3}{|l|}{ Age } \\
\hline$\leq 20$ & 29 & 7.9 \\
\hline $21-30$ & 230 & 62.8 \\
\hline $31-40$ & 57 & 15.6 \\
\hline $41>$ & 50 & 13.7 \\
\hline
\end{tabular}

In this study, respondents were asked regarding the duration of traffic congestion which they experienced in 
Klang Valley highways. The result in Table 3 shows the duration of the time spend on traffic congestion. Out of the total population sampled, $173(47.3 \%)$ stated that they spent about 15 to 30 minutes every day on traffic congestions before they reach destinations. About $26.5 \%$ spent less than 15 minutes, $15 \%$ between 30 minutes to 1 hour, $8.7 \%$ between 1 hour to 1 and half hour and $2.5 \%$ between 1 and half hour to 2 hour.

Table 3. Duration of sitting in traffic congestion

\begin{tabular}{lll}
\hline Duration & Frequency & Percentage \\
\hline Less than 15 minutes & 97 & 26.5 \\
15 to 30 minutes & 173 & 47.3 \\
30 minutes to1 hour & 55 & 15.0 \\
1 hour to 1 and half hour & 32 & 8.7 \\
1 and half hour to 2 hour & 9 & 2.5 \\
Total & 366 & 100.0 \\
\hline
\end{tabular}

The respondents were also asked about their monthly budget allocation on vehicles. As can be seen from Table 4, on average, respondents spend a larger share of their budget on vehicle maintenance which cost RM648 per month. About RM309 will be spent on fuel and RM110 on toll payment.

Table 4. Monthly expenditure on vehicles

\begin{tabular}{ll}
\hline Budget allocation on vehicles & Monthly Expenditure in Ringgit Malaysia (RM) \\
\hline Fuel & RM309 \\
Toll payment & RM110 \\
Vehicle maintenance cost & RM648 \\
\hline
\end{tabular}

\subsection{Logit Analysis of WTP for Reducing Traffic Congestion}

Estimation results for logit analysis of WTP for reducing traffic congestion is shown in Table 5. The willingness to pay (WTP) equation was estimated using E-Views Version 9 to determine the relationship between WTP and each of the variables as earlier discussed.

Table 5. Results of the regression analysis to the WTP model

\begin{tabular}{lllll}
\hline Variables & Coefficient & Standard Error & t-stat & p-value \\
\hline Price Bid & $-0.600^{* *}$ & 0.243 & -2.464 & 0.0137 \\
Household Income & $0.0001^{* * *}$ & $2.11 \mathrm{E}-05$ & 5.539 & 0.000 \\
Occupation & $-0.211^{*}$ & 0.124 & -1.694 & 0.090 \\
Constant & 0.746 & 0.618 & 1.206 & 0.227 \\
LR statistic & 45.1763 & & & \\
Prob (LR statistic) & 0.0001 & & & \\
Observations & 366 & & & \\
\hline
\end{tabular}

Notes: $* * *, * *$ and $*$ denote significance at the $1 \%, 5 \%$ and $10 \%$ significance levels, respectively.

The problem considered in this study is to reduce traffic congestion and transport externalities such as air pollution, accidents, extra travelling time and others at the highway. The results show that household income, occupation and price bid are statistically significant $(\mathrm{p}<0.10)$ in affecting the individual's WTP for reducing traffic congestion. These results indicate there was a significant positive correlation between willingness to pay and household income, when household income increases, the individual's WTP also increases. Whereas, price bid of toll payment and occupation portray negative relationship towards WTP, as the relationship between income and WTP is consistent with the demand theory, price increases, quantity demanded decreases. In order to assess the overall goodness-of-fit of the model, the log likelihood function is evaluated at the mean of the 
estimated parameters of the logit model. The results show that the Likelihood Ratio (LR) test has the value of 45.17 , with the probability of 0.0001 , indicating that the null hypothesis can be rejected at $1 \%$ level. Thus, we can conclude that the present model is very good fit.

With regard to the estimated WTP, the calculated road users' WTP ranges from RM0.23 (minimum) to RM6.39 (maximum) for all toll payments in Klang Valley highways. This study follows Cameron (1988) (refer to Equation 10) to determine road user's willingness to pay for reducing traffic congestion and reducing transport externalities in Klang Valley highways.

$$
\mathrm{WTP}=\left[\beta_{0}+\left(\beta_{\mathrm{HINC}} * \mathrm{HINC}+\beta_{\mathrm{OCC}} * \text { OCC }\right)\right] /-\left(\beta_{\mathrm{PBID}}\right)
$$

Where, $\beta_{\mathrm{HINC}}, \beta_{\mathrm{OCC}}$ and $\beta_{\mathrm{PBID}}$ illustrate estimated variables for household income, occupation, and price bid. Thus, the mean WTP computed from this study is RM1.95 for logit model.

\section{Conclusion}

The main focus of this study was to determine road users' willingness to pay for reducing traffic congestion. Some commuters believed it is the sole responsibility of government and highway concessionaire to provide better services in order to meet all relevant quality, safety and regulatory requirements and standards. The mean WTP of all road users' in Klang Valley for toll payment is RM1.95. Most of the respondents were willing to pay for eradication of transport externalities, though at different price bids and according to their household income, and occupation. To a very large extent, highway concessionaire still plays a major role in terms of providing efficient and safe expressway network for all stakeholders which can enhance quality of life.

The study gives support to the current strategy of improving the public transportation system. The willingness to pay for eradication of externalities was from the respondents who had higher income only. Those with lower income would be expected to also insist on the removal of the above mentioned externalities but due to their inability to pay would be more tolerant to the inconveniences. It calls for the government to make a more vigorous effort to improve public transportation which until now is perceived as either inadequate or just poor. The planning of public utilities by the responsible authorities needs to be better so as to eliminate the oft occurring circumstances of facilities reaching maximum usage capacity immediately upon completion.

Decision makers are therefore encouraged to make a wise resolution on how to reduce traffic congestion efficiently. Results of the study indicate there is a need for improvements for the public transportation system in the Klang Valley. Therefore, government and various stakeholders should ensure better control on the public transport services mostly on the services schedule that would attract non-public transport users to start taking public transport. By providing high quality traffic option, it is likely to motivate motorist to move from private vehicles to public transportation, mainly during peak hours for uncongested travel.

Other congestion reduction strategies, such as competent road pricing, pricing reform, roadway expansion, traffic signal synchronization, automated highway technologies, intersection flyovers, wider and straighter lanes, additional traffic lanes, improvements to alternative modes and utterly new roadways, to name a few, are likely to reduce traffic congestion. Although these strategies do not necessarily eliminate congestion, yet they improve overall accessibility and provide solutions to congestion problems.

\section{Acknowledgements}

We sincerely acknowledge the financial support from the Ministry of Higher Education, Malaysia (MOHE) through the project Exploratory Research Grant Scheme (ERGS) 55076. The authors are jointly responsible for any inadvertent errors.

\section{References}

Alberini, A. (1995). Testing Willingness-To-Pay Models Of Dichotomous Choice Contingent Valuation Data. Land Economics, 71(1), 83-95. http://dx.doi.org/10.2307/3146760

Asensio, J., \& Matas, A. (2008). Commuters' valuation of travel time variability. Transportation Research Part E, 44(6), 1074-1085. http://dx.doi.org/10.1016/j.tre.2007.12.002

Bishop, R. C., \& Heberlein, T. A. (1980). Simulated Markets, Hypothetical Markets, and Travel Cost Analysis: Alternative Methods of Estimating Outdoor Recreation Demand. Staff Paper Series No. 187. Department of Agricultural Economics, University of Wisconsin, Madison, WI.

Bjorner, T. B. (2004). Combining socio-acoustic and contingent valuation surveys to value noise reduction. Transportation Research Part D, 9(5), 341-356. http://dx.doi.org/10.1016/j.trd.2004.05.002

Boyle, K. J., Bishop, R. C., \& Welsh, M. P. (1985). Starting point bias in contingent valuation bidding games. 
Land Economics, 61, 188-194. http://dx.doi.org/10.2307/3145811

Brownstone, D., Ghosh, A., Golob, T. F., Kazimi, C., \& Amelsfort, D. V. (2003). Drivers' willingness-to-pay to reduce travel time: Evidence from the San Diego I-15 congestion pricing project. Transportation Research Part A, 37(4), 373-387. http://dx.doi.org/10.1016/s0965-8564(02)00021-6

Calfee, J., \& Winston, C. (1998). The value of automobile travel time: Implications for congestion policy. Journal of Public Economics, 69(1), 83-102. http://dx.doi.org/10.1016/S0047-2727(97)00095-9

Cameron, T. A. (1988). A new paradigm for valuing non-market goods using referendum data: maximum likelihood estimation by censored logistic regression. Journal Environmental Economics and management, 15, 355-379. http://dx.doi.org/10.1016/0095-0696(88)90008-3

Dodgson, J., \& Lane, B. (1997). The Costs of Road Congestion in Great Britain. A Nera Briefing Paper. National Economic Research Associates, 15 Stratford Place, London W1N 9AF.

Eboli, L., \& Mazzulla, G. (2008). Willingness-to-pay of public transportation users for improvement in services quality. European Transport, 38, 107-118.

Fosgerau, M., \& Bjorner, T. B. (2006). Joint models for noise annoyance and willingness to pay for road noise reduction. Transportation Research Part B, 40(2), 164-178. http://dx.doi.org/10.1016/j.trb.2005.03.001

Gerking, S., Dickie, M., \& Veronesi, M. (2014). Valuation of human health: An integrated model of willingness to pay for mortality and morbidity risk reductions. Journal of Environmental Economics and Management, 68, 20-45. http://dx.doi.org/10.1016/j.jeem.2013.11.010

Gujarati, D. (2003). Basic Econometrics (4th ed.). New York: McGraw Hill.

Haneman, M., Loomis, J., \& Kanninen, B. (1991). Statistical efficiency of double bounded dichotomous choice valuation. American Journal of Agricultural Economics, 73, 1255-1263. http://dx.doi.org/10.2307/1242453

Hanemann, W. M. (1984). Welfare evaluations in contingent valuation experiments with discrete responses. American Journal of Agricultural Economics, 66, 332-334. http://dx.doi.org/10.2307/1240800

Hanemann, W. M. (1989). Welfare evaluations in contingent valuation experiments with discrete response data: Reply. American Journal of Agricultural Economics, 71(4), 1057-1061. http://dx.doi.org/10.2307/1242685

Kaliba, A. R., \& Ghebreyesus, G. S. (2011). Priority and willingness to pay for improving primary education in Tanzania. Educational Research, 2(2), 898-909.

Malaysia Kuala Lumpur city road map and highway map. Retrieved from October 9, 2015, from http://www.malaxi.com/map_kuala_lumpur_highway_road.html

Mitchell, R. C., \& Carson, R. T. (1989). Using Surveys to Value Public Goods: The Contingent Valuation Method. Johns Hopkins University Press, Baltimore, MD.

Ortuzar, J. D., Cifuentes, L. A., \& Williams, H. C. W. L. (2000). Application of Willingness-to-Pay Methods to Value Transport Externalities in Less Developed Countries. Environmental and Planning A, 32, 2007-2018. http://dx.doi.org/10.1068/a3324

Pearce, D., \& Ozdemiroglu, E. (2002). Economic valuation with stated preference techniques: Summary guide. London: Department for Transport, Local Government and the Regions.

Portal Lembaga Lebuhraya Malaysia. (2014). Retrieved from http://www.llm.gov.my/

Santos, G., Behrendt, H., Maconi, L., Shirvani, T., \& Teytelboym, A. (2010). Part I: Externalities and Economic Policies in Road Transport. Research in Transportation Economics, 28(1), 2-45. http://dx.doi.org/10.1016/ j.retrec.2009.11.002

Sexton, S. E., \& Sexton, A. L. (2014). Conspicuous conservation: The Prius halo and willingness to pay for environmental bona fides. Journal of Environmental Economics and Management, 67, 303-317. http://dx. doi.org/10.1016/j.jeem.2013.11.004

Surendran, A., \& Sekar, C. (2010). An economic analysis of willingness to pay (WTP) for conserving the biodiversity. International Journal of Social Economics, 37(8), 637-648. http://dx.doi.org/10.1108/0306829 1011060661

Takada, K., \& Fujiu, M. (2010). Study of willingness to pay for reducing lost time of railway users. Journal of the Eastern Asia Society for Transportation Studies, 8, 1464-1474.

Tietenberg, T. (2000). Environmental and natural resource economics (5th ed.). United States of America: 
Addison Wesley Longman, Inc.

Tietenberg, T., \& Lewis, L. (2008). Environmental and natural resource economics (8th ed.). USA: Pearson Education.

Wedgwood, A., \& Sansom, K. (2003). Willingness-to-pay surveys- a streamlined approach - guidance notes for small town water services. Southborough University, Program on Water, Engineering and Development Centre. Retrieved from http://siteresources.worldbank.org/INTWSS/Resources/WSS8fin4.pdf

Whittington, D. (1998). Administering contingent valuation surveys in developing countries. World Development, 26(1), 21-30. http://dx.doi.org/10.1016/S0305-750X(97)00125-3

\section{Copyrights}

Copyright for this article is retained by the author(s), with first publication rights granted to the journal.

This is an open-access article distributed under the terms and conditions of the Creative Commons Attribution license (http://creativecommons.org/licenses/by/3.0/). 